\title{
Implementação de melhorias para o Objeto de Aprendizagem BBE (Blinds, Basic Education)
}

$\underline{\text { Kayo Costa de Santana }}{ }^{1}$; Claudia Pinto Pereira ${ }^{2}$

1. Bolsista PIBIC/FAPESB, Graduando em Engenharia de Computação, Universidade Estadual de Feira de Santana, e-mail: kayo.santana@hotmail.com

2. Orientador, Departamento de Ciências Exatas, Universidade Estadual de Feira de Santana, e-mail: claudiap@uefs.br

PALAVRAS-CHAVE: BBE; Inclusão Social; Objeto de Aprendizagem.

\section{INTRODUÇÃO}

O Censo 2010 (IBGE, 2010) mostra que aproximadamente 35.8 milhões de brasileiros possuem algum tipo de deficiência visual. Mesmo com um quantitativo tão significativo de pessoas com deficiência visual, a acessibilidade no Brasil ainda é precária (REIS, 2014) e, mesmo quando o acessível é conquistado, ainda existem vários desafios para serem enfrentados. Ainda segundo os dados do IBGE (2010), a quantidade de pessoas com deficiência visual matriculadas em escolas públicas vem crescendo e, com isso, é necessário que se encontrem meios para tornar a educação ainda mais inclusiva, buscando métodos para progredir e apresentar resultados justos e eficazes para todos.

A utilização das tecnologias de informação e comunicação (TIC) expande a possibilidade de aprendizagem e promove um cenário educacional mais capacitado, permitindo, assim, condições de acesso e permanência no sistema educacional [RICOY e COUTO, 2009]. Utilizando-se destes conceitos, surgem os Objetos de Aprendizagem, que são ferramentas capazes de fortalecer o processo de ensino e aprendizagem, como, por exemplo, a ferramenta BBE (Blinds, Basic Education), criada em 2015/2016 e com novas funcionalidades neste trabalho, com o intuito de auxiliar ainda mais os professores no processo de ensino, e os alunos, com ou sem deficiência visual, no processo de aprendizagem.

Uma das formas encontradas para facilitação do processo de ensinoaprendizagem é o uso das TIC. A ferramenta desenvolvida através de recursos tecnológicos favorece a inclusão de pessoas com deficiência, promovendo, assim, novas oportunidades e possibilidades para esse público que, mesmo com os avanços tecnológicos, ainda precisa superar muitos obstáculos, sendo o BBE uma proposta para que o processo educacional se torne mais democrático e inclusivo [SANTANA, 2016]

O BBE é um jogo multidisciplinar, ou seja, trabalha com várias disciplinas e/ou conceitos, permitindo trabalhar uma gama de disciplinas simultaneamente, ainda que sem relação evidente entre elas [JAPIASSÚ, 1976]. Os jogos educacionais com caráter multidisciplinar, como, por exemplo, o BBE, são capazes de atrair diversos públicos, pela possibilidade de trabalhar com diversos tipos e níveis de conhecimento. Como objetivos desse plano foram propostas a consolidação e a divulgação da ferramenta, através da implementação de melhorias, de novas funcionalidades (modo singleplayer, sistema de ranking, exibição de pontuação) e a realização de questionários para a validação de funcionamento e verificação de melhorias para a ferramenta. Através do cumprimento destes, foi possível oferecer ao seu público uma ferramenta melhor, que se adequasse mais aos recursos que garantem acessibilidade e, até mesmo, uma melhor 
usabilidade do software, salientando a importância da ferramenta para fortalecer o processo de ensino e aprendizagem através da ludicidade.

\section{MATERIAL E MÉTODOS OU METODOLOGIA (ou equivalente)}

A ferramenta foi desenvolvida através do uso de um computador pessoal e fontes de pesquisas encontradas na internet relacionadas às tecnologias. $\mathrm{O}$ jogo, criado utilizando a linguagem de programação Java e síntese de voz de um projeto que utiliza o MBrola $^{1}$ e Cloudgarden ${ }^{2}$, nessa nova versão, teve sua interface gráfica recriada através do JavaFX ${ }^{3}$.

Para a validação da ferramenta, foi necessária a criação dos questionários e submissão destes e outros documentos (Termo de Assentimento Livre e Esclarecido, Termo de Consentimento Livre e Esclarecido, Cronograma, Orçamento Financeiro, entre outros) na Plataforma Brasil, para a aceitação da pesquisa pelo Comitê de Ética. Após aceita a pesquisa, foi iniciada a divulgação e aplicação da ferramenta, sendo então possível validar não só como um objeto de aprendizagem capaz de auxiliar o ensino e a aprendizagem, como também nos seus quesitos técnicos e de funcionalidade.

Em paralelo com a submissão dos documentos para o Comitê de Ética, iniciouse o desenvolvimento das novas funcionalidades e melhorias, começando pela criação de novas interfaces para todas as telas trazendo assim uma melhor aparência. Posteriormente, foi implementado o modo singleplayer, que permite que o usuário jogue contra o computador, além do sistema de pontuação e ranking. Por fim, foi criado um "modo dica" que auxilia a percepção da pessoa com deficiência visual em conhecer o jogo nas primeiras vezes que joga, podendo ser desativado quando se familiarizar com a ferramenta.

A pesquisa, composta por três questionários que totalizam 30 questões objetivas e uma subjetiva, foi realizada com 3 grupos, sendo estes: professores do Curso de Engenharia de Computação da Universidade Estadual de Feira de Santana, estudantes do mesmo curso e, por fim, pessoas com deficiência visual da Fundação Jonathas Telles de Carvalho. Estes grupos foram utilizados para validar, não só os aspectos técnicos da ferramenta, como também seu caráter social e sua aplicação como um objeto de aprendizagem.

\section{RESULTADOS E/OU DISCUSSÃO}

A ferramenta desenvolvida encontra-se em funcionamento, para tanto, todos os resultados propostos foram alcançados, permitindo, assim, que as melhorias fossem implementadas conforme às necessidades de seu público e sempre pensando em melhores escolhas que contemplem suas particularidades. Além destas melhorias, foram implementadas também as novas funcionalidades, além de avaliada a ferramenta, não só com o público alvo, como também com professores, em relação à sua qualidade técnica e buscando melhorias para possíveis bugs ou até mesmo implementações melhores de certas funcionalidades.

O modo singleplayer, o sistema de ranking e de pontuação foram implementados e se encontram em funcionamento. Através deles, o usuário é capaz de jogar contra o computador, contabilizar pontos e, até mesmo, possuir seu nome em uma colocação do ranking, tornando a ferramenta ainda mais lúdica, através da utilização de conceitos de gamification.

\footnotetext{
${ }^{1}$ Para mais informações: http://intervox.nce.ufrj.br/lianetts/mbrola.htm

${ }^{2}$ Para mais informações: http://www.devmedia.com.br/artigo-java-magazine-04-javaspeech/8916

3 Para mais informações: http://docs.oracle.com/javase/8/javafx/get-started-tutorial/jfx-overview.htm\#JFXST784
} 
A nova versão do BBE, além das novas funcionalidades já descritas, possui uma possibilidade de variação de temas, que possibilita um melhor contraste para pessoas com baixa visibilidade. As novas telas estão mais organizadas tentando manter uma padronização que auxilia a experiência do usuário. Da mesma forma, a interface vocal, foi ao máximo padronizada, melhorando também a experiência do deficiente visual com perda total de visão. Além disso, foram adicionados atalhos que permitem uma melhor experiência e percepção para o deficiente visual.

Os três grupos que avaliaram a ferramenta totalizaram 22 pessoas, sendo 5 destes pessoas com deficiência visual. $O$ grupo de deficientes visuais avaliou $o$ questionário de validação da ferramenta como um objeto de aprendizagem com nota máxima (concordo totalmente) em todos os quesitos, mostrando que a ferramenta atende a sua proposta de auxiliar a inclusão sociodigital destas pessoas. Dos outros grupos, foi obtido mais de $95 \%$ de aceitação (concordo parcialmente e totalmente) em todas as perguntas, sendo uma única pergunta respondida como discordo parcialmente (no item que perguntava se através da ferramenta era possível exercitar o raciocínio lógico). Assim, através destes resultados, foi possível validar o BBE como uma ferramenta capaz de auxiliar no processo de ensino e aprendizagem, através de um ensino lúdico. Vale salientar que o público-alvo atribuiu nota máxima em todos os quesitos, mostrando assim que a ferramenta auxilia a inclusão sociodigital e fortalece os meios alternativos de aquisição de conhecimento para este público. Os resultados gerais correspondem à análise das perguntas do quadro 1 e podem ser visualizados no gráfico 1 .

Quadro 1: Perguntas utilizadas no questionário

P1- O jogo é divertido

P2- Através do jogo é possível exercitar assuntos de diversas disciplinas

P3- Através do jogo é possível treinar/aprender assuntos de diversas disciplinas

$\mathrm{P} 4-\mathrm{O}$ jogo permite que os assuntos sejam exercitados de maneira divertida

P5- O jogo tornou o processo educacional mais interessante

P6- A ferramenta é uma aliada para o processo de ensino-aprendizagem

P7- O jogo pode tornar o ensino e a aprendizagem mais interessante

P8- Eu utilizaria o jogo para exercitar algum conteúdo educacional

P9- Através da ferramenta é possível exercitar o raciocino lógico para vencer através do preenchimento do tabuleiro

P10- No geral, eu considero o BBE uma ferramenta boa para auxiliar o processo de aprendizagem

Gráfico 1: Análise geral do BBE (Objeto de Aprendizagem)

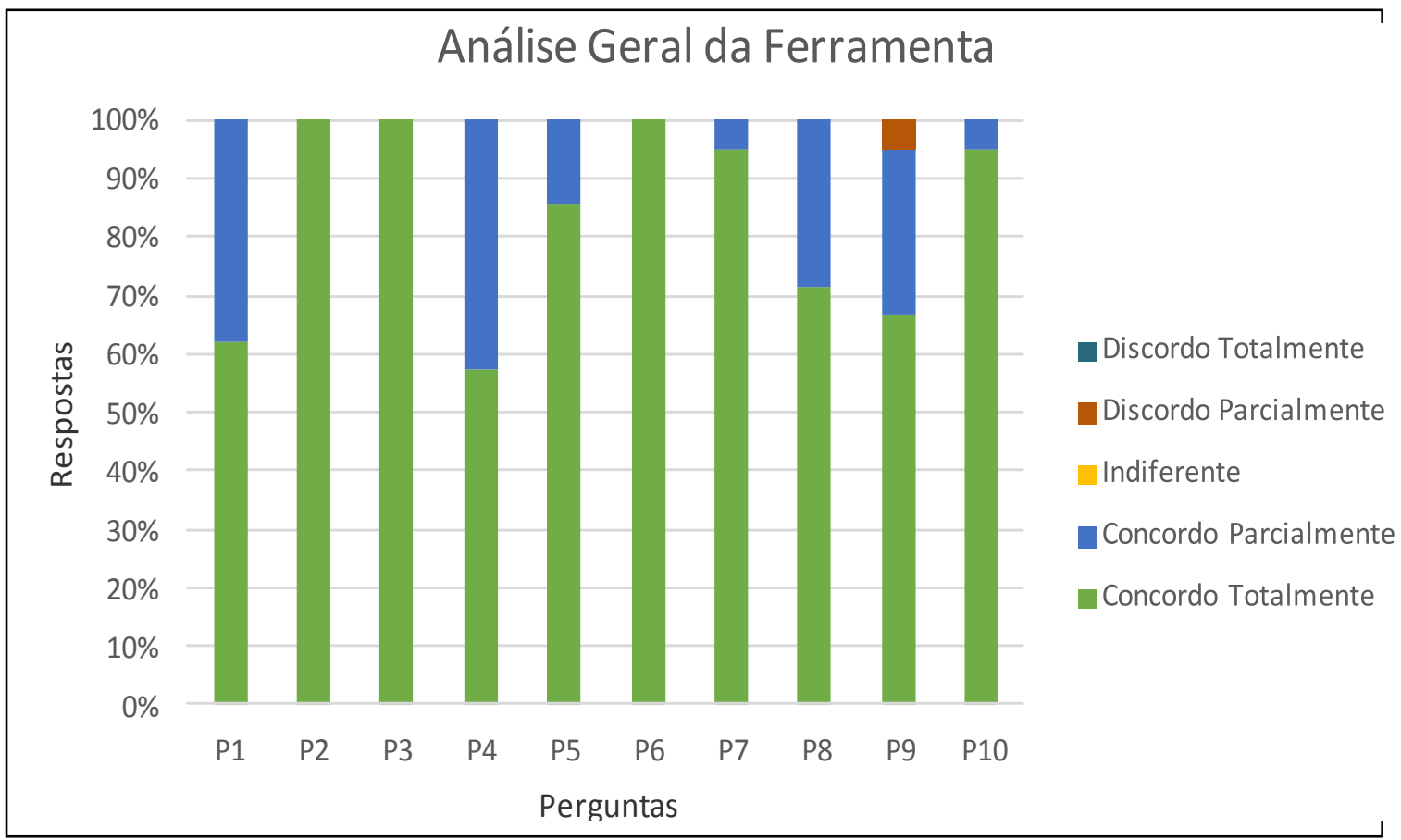


Vale salientar que estes resultados foram analisados por cada um dos grupos pesquisados e foram submetidos em forma de artigo para o XXVIII SIMPÓSIO BRASILEIRO DE INFORMÁTICA NA EDUCAÇÃO, com resumo aprovado, em primeira instância, aguardando, no momento, avaliação final.

\section{CONSIDERAÇÕES FINAIS (ou Conclusão)}

O Blinds Basic Education (BBE) se encontra em funcionamento, todas as suas funcionalidades podem ser acessadas tanto pelo mouse quanto pelo teclado, com o uso da interface gráfica ou vocal. Através da ferramenta, é possível que o usuário aprenda e exercite componentes curriculares através da diversão proporcionada pelo jogo, hipótese essa que foi comprovada através da realização dos questionários.

É imprescindível também ressaltar o crescimento da ferramenta através da implementação de suas melhorias, podendo agora ser disponibilizada para o público, com a implementação de outros módulos e a solução de alguns bugs, contribuindo assim para um processo de ensino e aprendizagem mais acessível e democrático para todos.

Outro aspecto importante foi a experiência trazida como a realização de pesquisa com pessoas, visto que, ao submeter a pesquisa para a análise de um Comitê de Ética, foi possível entender a importância de realizar a pesquisa, conforme às resoluções impostas, visando um momento melhor entre o pesquisador e a pessoas que se voluntariaram para a pesquisa.

\section{REFERÊNCIAS}

IBGE (2010). CENSO 2010. Disponível em: http://www.cod.ibge.gov.br/234d0. Acesso em 20 jun. 2017.

JAPIASSÚ, H. (1976) “Interdisciplinaridade e Patologia do saber”. Rio de Janeiro: Imago.

REIS, T.; MORENO, A. C.. Maioria das escolas públicas não tem acessibilidade nem rede de esgoto. Disponível em: <http://g1.globo.com/educacao/noticia/2014/07/maioria-das- escolaspublicas- nao-tem-acessibilidade-nem- rede-de- esgoto.html>. Acesso em 04 abr. 2017.

RICOY, M C.; COUTO, M. J. V. S. (2009). "As tecnologias da informação e comunicação como recursos no Ensino Secundário: um estudo de caso". Rev. Lusófona de Educação, Lisboa, n. 14. Disponível em <http://www.scielo.mec.pt/scielo.php?script=sci_arttext\&pid=S1645$72502009000200010 \& \operatorname{lng}=$ pt\&nrm=iso>. Acessos em : 29 abr. 2017.

SANTANA, K. C.(2016). "Implementação de melhorias para o objeto de aprendizagem BBE (Blinds,Basic Education)". Plano de Trabalho. 